\title{
Green chemistry and the biorefinery: a partnership for a sustainable future
}

\author{
James H. Clark, * Vitaly Budarin, Fabien E. I. Deswarte, Jeffrey J. E. Hardy, $\uparrow$ Fran M. Kerton, $\ddagger$ \\ Andrew J. Hunt, Rafael Luque, Duncan J. Macquarrie, Krzysztof Milkowski, Aitana Rodriguez, \\ Owain Samuel, Stewart J. Tavener, Robin J. White and Ashley J. Wilson
}

\author{
Received 27th March 2006, Accepted 24th July 2006 \\ First published as an Advance Article on the web 14th August 2006 \\ DOI: $10.1039 / \mathrm{b} 604483 \mathrm{~m}$
}

\begin{abstract}
Research into renewable bioresources at York and elsewhere is demonstrating that by applying green chemical technologies to the transformation of typically low value and widely available biomass feedstocks, including wastes, we can build up new environmentally compatible and sustainable chemicals and materials industries for the 21 st century. Current research includes the benign extraction of valuable secondary metabolites from agricultural co-products and other low value biomass, the conversion of nature's primary metabolites into speciality materials and into bioplatform molecules, as well as the green chemical transformations of those platform molecules. Key drivers for the adoption of biorefinery technologies will come from all stages in the chemical product lifecycle (reducing the use of non-renewable fossil resources, cleaner and safer chemical manufacturing, and legislative and consumer requirements for products), but also from the renewable energy industries (adding value to biofuels through the utilisation of the chemical value of by-products) and the food industries (realising the potential chemical value of wastes at all stages in the food product lifecycle).
\end{abstract}

\section{Introduction}

While the 20th century saw the emergence and establishment of an organic chemicals manufacturing industry based on petroleum refining, the 21 st century will see the development of a new organics industry based on biomass refining. ${ }^{1-3}$ In both scenarios the driver is energy. The enormous demand for petroleum as a cheap, single-use fuel gave chemical manufacturing a large volume, low cost and continuous supply of hydrocarbons from which the petrochemical industry was built; chemical and engineering technology for cracking, separating, rearranging, polymerising and functionalising allowed us to take complex mixtures of simple chemicals and transform them into a multitude of higher value molecules with a seemingly never-ending range of applications from high volume, low cost plastics to small volume but highly expensive drugs. We are now at the beginning of an era where new, renewable sources of energy are sought with increasing vigour; biomass, renewable carbon, is guaranteed a place in the new energy portfolio for the foreseeable future. The growth in the bioenergy (e.g. biomass gasification) and biofuels (e.g. biodiesel) industries will add to the food industries in the consumption of renewable carbon. ${ }^{2}$ Food production is wasteful-from the crop residues (e.g. wheat straw) through the processing (where substantial losses occur) to sale and consumption, we throw away an obscenely high proportion of food. However, what is waste to food manufacturing can be

Green Chemistry Centre of Excellence, Department of Chemistry, University of York, York, UK YO10 5DD

$\dagger$ Current address: Royal Society of Chemistry, Burlington House, Piccadilly, London W1J 0BG

\# Current address: Department of Chemistry, Memorial University of Newfoundland, St Johns, NLA1B 3X7, Canada. feed to the chemicals, energy and other industries. Wheat straw contains significant quantities of valuable wax compounds (fatty alcohols, alkanes, etc) and the lignocellulosic fraction can be used to make paper or ethanol; ${ }^{4}$ rice husks from rice farming can be burned to yield the energy needed to drive the farm machinery, and the residues are rich in silica ${ }^{5}$ that has diverse application value. Used food oils can be recovered and, through chemical transformation, turned into biodiesel. ${ }^{6}$ The same biodiesel manufacturing process, encouraged by tax incentives and government targets for biofuel utilisation, produces glycerol as a co-product, which, through the right chemistry, can be turned into numerous higher value products. Food wastes can no longer be landfilled due to health concerns, so they ultimately need to be burned; alternatively they could be gasified and used to drive a gas turbine to produce electricity - combined heat and power units is an exciting possibility for the destination of low value residues and wastes. It may also be possible to gain chemical value from the destruction of food (and other biological) wastes; controlled pyrolysis can be used to produce small organic molecules that may have value in their own right, or in making polymeric materials, or as platform molecules for building up larger and more valuable chemical products. ${ }^{7}$

The refining of nature's daily bounty will provide a treasure trove of chemical potential from pre-treatment to incineration, as well as by devoting some of the raw material to bioprocessing.

A biorefinery can be considered as an integral unit that can accept different biological feedstocks and convert them to a range of useful products including chemicals, energy and materials (Fig. 1). ${ }^{8,9}$

Renewable resources research at York is directed at chemical aspects of biomaterials and bioenergy as well as 


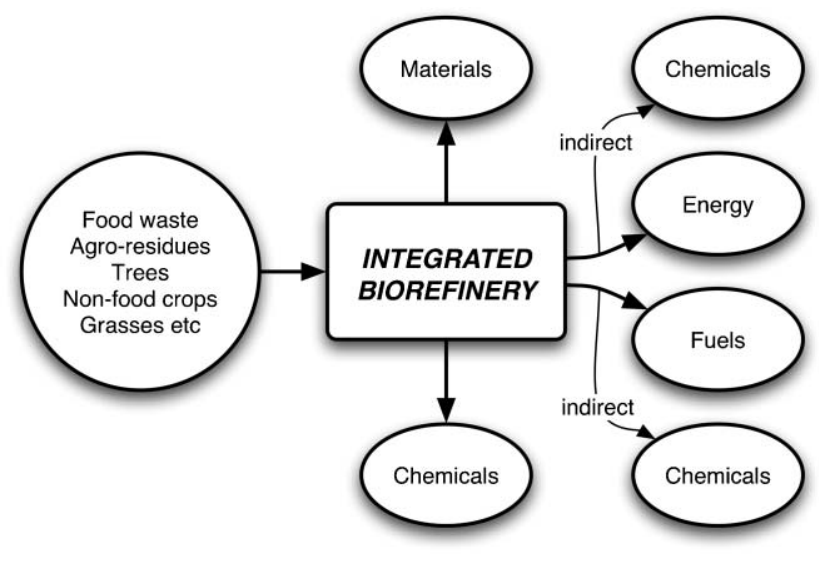

Fig. 1 The integrated biorefinery as a mixed feedstock source of chemicals, energy, fuels and materials.

bio-chemicals (Fig. 2) ${ }^{10}$ Based on a wide range of renewable feedstocks (including low value plants such as trees, grasses and heathers; energy crops and food crops by-products; marine resource wastes and food wastes) we research the application of green chemical technologies (including supercritical fluid extraction; microwave processing; catalytic and other clean synthesis methods) with the aim of developing new, genuinely sustainable, low environmental impact routes to important chemical products, materials and bioenergy. In this article, we will outline with some new examples some of the key project areas in which we are currently engaged.

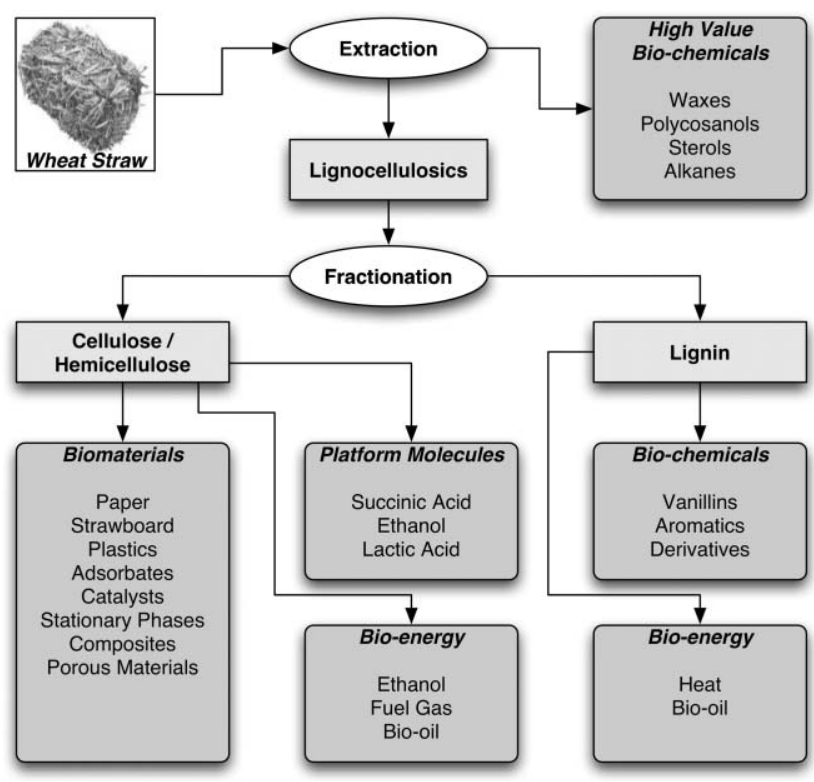

Fig. 3 The wheat straw biorefinery concept.

\section{Supercritical fluid extraction of secondary metabolites from plant surfaces}

Wheat straw is a good example of a low value, high volume agricultural by-product that can be the basis for a biorefinery. Materials, chemicals and bioenergy/fuels are all accessible from this chemically interesting feedstock (Fig. 3). ${ }^{11}$

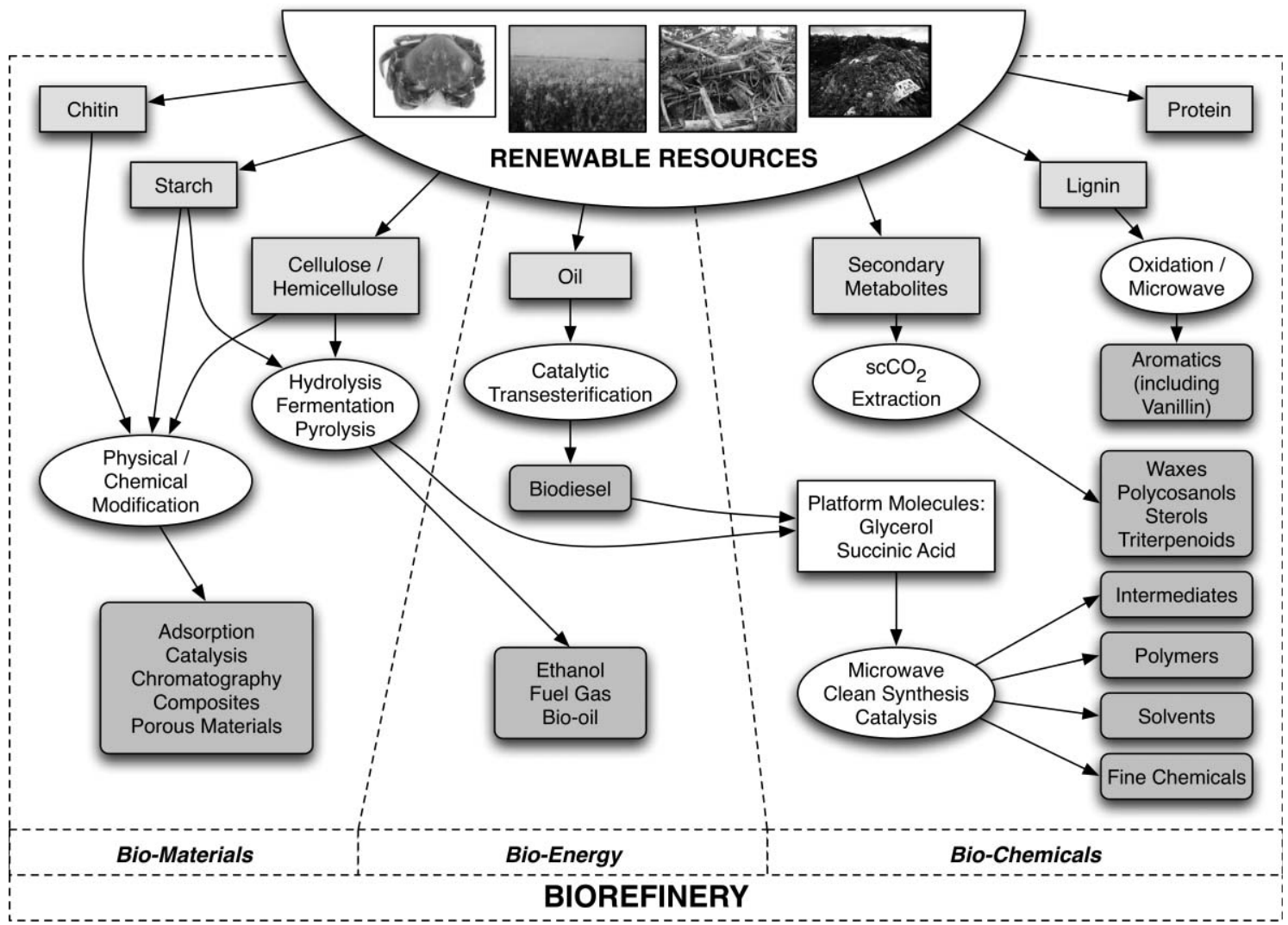

Fig. 2 Renewable Resources research at York: applying green chemistry to the biorefineries. 
We recently reported the first successful use of supercritical fluid (SF) extraction and fractionation of waxes from wheat straw. ${ }^{4}$ This can be considered as the first step in a biorefinery, with no effect on the bulk structure of the straw. Plant waxes are a complex mixture of linear compounds notably long chain alkanes, fatty alcohols and acids, and cyclic compounds, especially sterols, and while there is value in the mixture, more refined fractions can have much greater value in areas including cosmetics, insect semiochemicals and nutraceuticals. ${ }^{4,12}$ Use of variable temperature and pressure $(T / P) \mathrm{scCO}_{2}$ allowed us to fractionate the waxes on the surface of wheat straw, and to totally avoid contamination from more polar unwanted compounds that are always present in solvent extraction. The area has added appeal in countries such as the UK where we import our plant waxes and where demand is outstripping supply. An important additional factor is a growing reluctance to use animal derived products (even extending to lanolin from sheep's wool).

The use of an environmentally low impact extraction and fractionation method combined with a low or zero value feedstock is clearly attractive on both environmental and economic grounds. The potential for providing new business opportunities to rural areas, where farming income, for example, has been at a record low, completes the 'triple bottom line benefit' through social advantage. ${ }^{13}$ We have extended the methodology to another UK-abundant low value plant material, heather (Calluna vulgaris). The new value in heather has a potentially important added benefit in that the poor economics of upland farming has been driving businesses away from these regions. There is a danger that these important regions will become unmanaged, with potentially devastating effects on water management - in the UK for example, some $70 \%$ of our fresh water supply comes from the uplands. ${ }^{14}$ The surface waxes on the above ground components of heather are typically complex. ${ }^{15} \mathrm{We}$ demonstrated that they were rich in valuable products such as triterpenoids. The selectivity advantage of $\mathrm{scCO}_{2}$ is immediately evident when comparing a typical extract with a solvent extract (Fig. 4). The chromatograms for these two mixtures are significantly different and of particular importance, the triterpenoids are almost absent from the former, both helping the purity of the $\mathrm{scCO}_{2}$-derived extracts and also providing a route to triterpenoid fractionation.

It is clear that applying a benign extraction/fractionation technique to abundant and low value plants to generate valuable products has multiple benefits, especially in regions where land resource management needs better control and where the wax products are largely imported. There is even the added benefit of surface wax extraction adding to the value of the materials for use in the bioenergy and paper industries. We have taken this method up to large scale in collaboration with industry, and new product formulations based on these
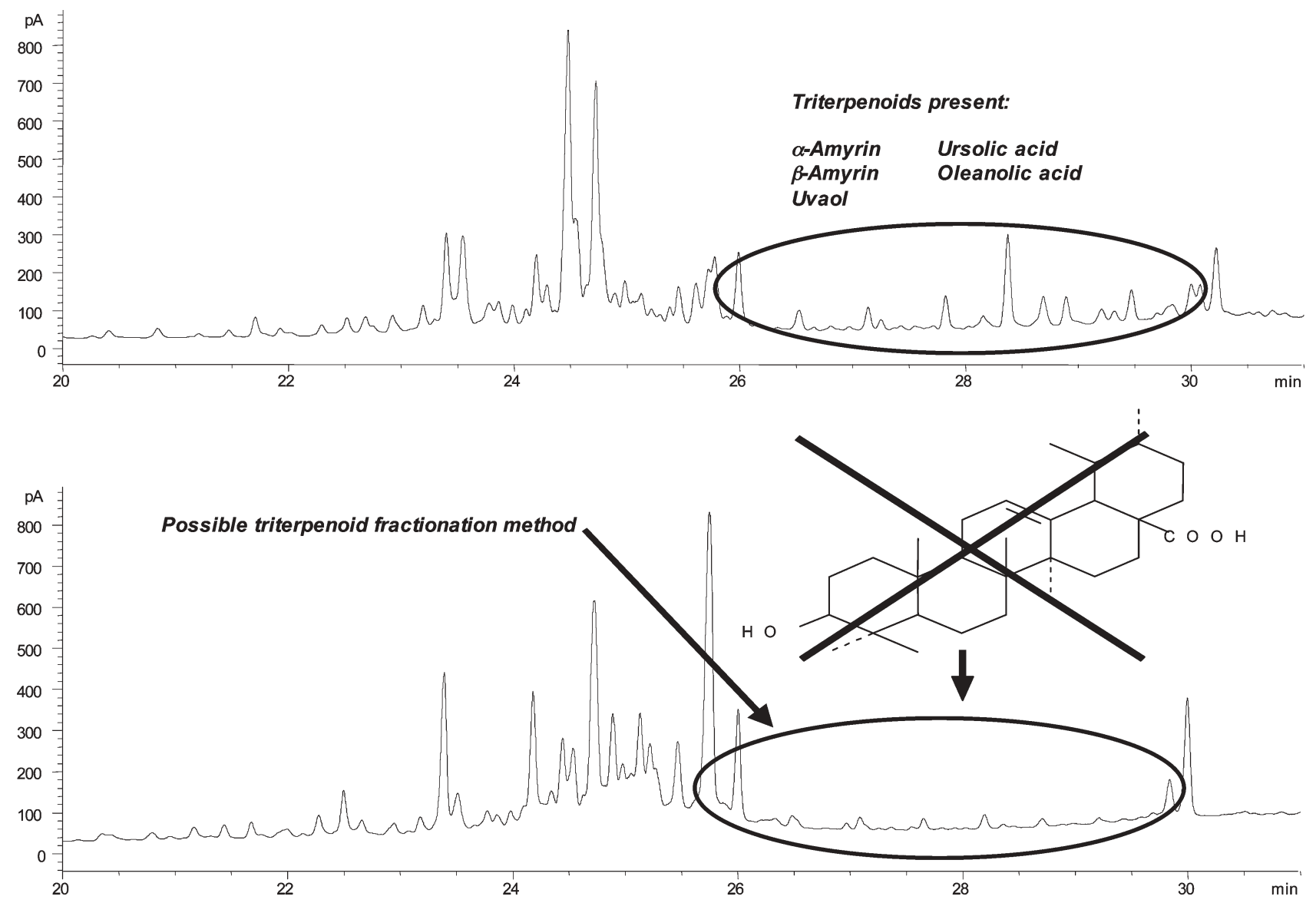

Fig. 4 Gas chromatograms of a solvent extracted sample from Calluna vulgaris (with triterpenoids present) and a supercritical carbon dioxide extracted sample (with no triterpenoids present). 
sustainable "green" chemicals are currently being developed and tested. ${ }^{4,12}$

\section{Trees as chemical factories}

Trees represent an enormous renewable carbon resource in many countries worldwide. ${ }^{2,16}$ In the UK for example, there are 2.7 million hectares of woodland. The total volume (standing biomass) of wood produced in the UK has been increasing over the past decade and future predictions suggest a continuing increase over the next twenty years. Trees planted during the boom of the 1970s and 1980s will come to maturity in the next decade, but prices for timber have slumped and the decline is continuing. Increasing supply at a time of low prices is likely to exacerbate current problems, and many plantations are unlikely to be worth extracting for timber or pulp. Finding ways of adding value to such wood resources will help stimulate rural enterprises and maintain the rural economy. This could include the utilisation of residues from the pulp and board industries such as bark. Other sources of wood currently not utilised include branches, although these can be widely scattered and their collection and transportation will consume resources. Alternatively, new wood-utilising industries could compete with the existing timber-based industries. Some examples of new applications include cellulose fibres for textiles and sawdust resins as adhesives.

Overall, only about a quarter of felled wood in Europe is converted to timber. The remainder is a rich composite of primary and secondary metabolites that are a largely unexploited resource for novel renewable products. Some of the green chemical technologies that we are applying to this challenge are shown in Fig. 5. In particular, we have been studying the major UK tree species, Sitka spruce.

We have already discussed the use of SF extraction for wheatstraw and heather. Trees are also rich in extractable secondary metabolites including terpenes, flavonoids, sterols and resin acids, as well as waxes. Some of these have been shown to be valuable including polyphenolic flavonoids as antioxidants. ${ }^{17}$

Among the major compounds in trees we have focused our attention on lignin and cellulose, each of which we will now discuss in more detail.

\section{Vanillin from lignin}

Lignin represents nature's greatest store of aromatic molecules and one of the greatest challenges chemists and biologists face is to find efficient and low environmental impact ways of unlocking that store. ${ }^{18}$ Petroleum has provided us with a cheap abundance of aromatic compounds from benzene upwards, and aromatic products in pharmaceuticals, agrochemicals, polymers and many other sectors have become well established. We need to develop sustainable sources of aromatic compounds that we can build up to help compensate for a future shortfall and increasing costs of petro-derived aromatic platform molecules such as phenol.

Vanillin is one useful aromatic compound that can be obtained directly from lignin., ${ }^{2,7}$ We have carried out preliminary studies comparing the yields of vanillin obtained by different methods of activation-conventional heating with

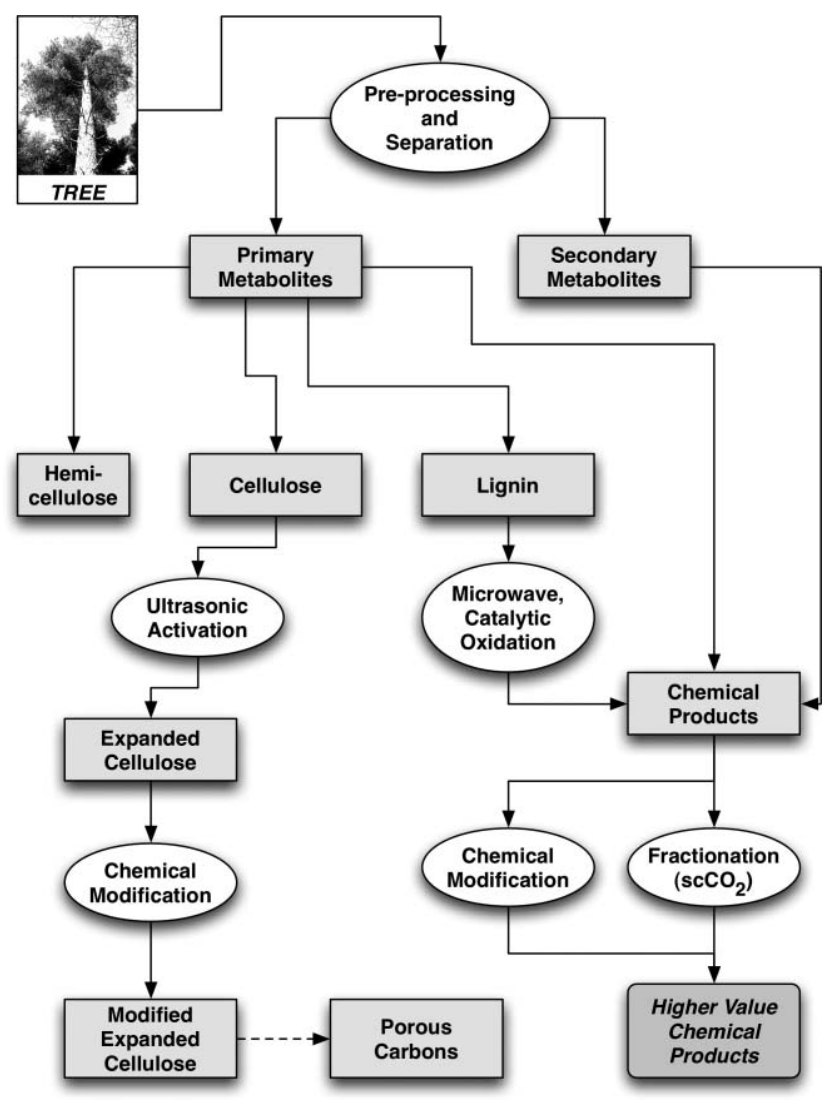

Fig. 5 Possible green chemical routes to exploit and add value to tree metabolites.

Table 1 Lignin oxidation routes to vanillin

\begin{tabular}{lll}
\hline Method & Conditions & $\begin{array}{l}\% \text { Vanillin (by } \\
\text { standardised } \\
\text { HPLC) }\end{array}$ \\
\hline Conventional heating & $2 \mathrm{~N} \mathrm{NaOH} / 160{ }^{\circ} \mathrm{C} / 24 \mathrm{~h}$ & 3.5 \\
Microwave & $2 \mathrm{~N} \mathrm{NaOH} / 160{ }^{\circ} \mathrm{C} / 15 \mathrm{~min}$ & 5.1 \\
Conventional heating & $\mathrm{FeCl}_{3}(0.5 \mathrm{wt} \%) / 160{ }^{\circ} \mathrm{C} / 24 \mathrm{~h}$ & 5.8 \\
Conventional heating & $\mathrm{CuSO}_{4}(0.5 \mathrm{wt} \%) / 160{ }^{\circ} \mathrm{C} / 24 \mathrm{~h}$ & 4.8 \\
\hline
\end{tabular}

base, microwave heating with base, and in the presence of redox metal salts (Table 1). In addition to vanillin, up to $1.3 \%$ vanillic acid was detected.

Clearly the use of microwave activation can have a dramatic effect on the reaction kinetics, which is especially important given how slow the reaction is under conventional heating. Even the presence of redox metal catalysts only causes a modest increase in the rate of reaction. We are currently investigating sequential reactions with different clean technologies, e.g. use of microwave activation to partly break down the lignin structure followed by catalytic oxidation using air or $\mathrm{H}_{2} \mathrm{O}_{2}$ as the two more environmentally friendly consumable sources of oxygen.

\section{Expanded biomaterials: high value applications for cellulose and starch}

We recently reported the first use of expanded starch as a stationary phase for liquid chromatography. ${ }^{19}$ The physical 
expansion of starch is achieved by a gelatinisation-retrogradation-dehydration process, whereby natural starch (potato, corn, pea, etc) with a surface area of $c a .1 \mathrm{~m}^{2} \mathrm{~g}^{-1}$ is converted into a material with a surface area of 100 $200 \mathrm{~m}^{2} \mathrm{~g}^{-1}$. As significantly, the starch is rendered mesoporous and with a particularly high mesopore volume/micropore volume compared to more traditional stationary phases, which is advantageous for chromatographic applications.

The initial gelatinisation step is achieved by heating in water, a process that causes swelling and then collapse of the starch granules giving a gel. Rapid gelatinisation can be achieved using microwave heating. There is even a rough correlation between the intensity of microwave radiation (fixed irradiation time but variable power) and the surface area of the final expanded material, with $300 \mathrm{~W}$ for 2 min giving a surface area of $>190 \mathrm{~m}^{2} \mathrm{~g}^{-1}$. The subsequent retrogradation occurs on maintaining the gel at low temperatures (above the glass transition temperature) that converts the amorphous state into a more ordered state. The rate of retrogradation is dependent on the amylose content of the starch, with high amylose content materials retrograding in a few hours, while those with higher proportions of the more structurally complex amylopectin require longer periods. The final dehydration process relies on controlled removal of the bulk of the water using solvent exchange and/or exchange using supercritical $\mathrm{CO}_{2}$.

The complete process for preparing expanded starch using ethanol in the solvent exchange is illustrated in Fig. 6. This includes scanning electron micrographs, which reveal dramatic differences between smooth, well-defined particles of normal starch and the irregular porous continuum of expanded starch. The expanded starches decompose at $c a .265{ }^{\circ} \mathrm{C}$, but at temperatures somewhat below that there is evidence (by variable temperature diffuse reflectance IR spectroscopy) for some chemical changes, with the appearance of a carbonyl band probably indicative of some cleavage between glucose units and the formation of aldehyde functions. Remarkably, in the presence of a small quantity of acid, expanded starch starts to decompose and form carbonaceous materials at temperatures as low as $100{ }^{\circ} \mathrm{C}$. We have nicknamed these materials "Starbons" since they have a combination of properties reminiscent of starch (high surface energy oxygenrich surfaces) and carbon (developing aromatic character, insolubility), while maintaining largely mesoporous structures even up to $700{ }^{\circ} \mathrm{C} .{ }^{20}$

The expanded starch was originally prepared as a separation medium for plant extracts - both to develop a more efficient stationary phase for complex mixtures of natural products and to keep a low environmental footprint for the whole process of extraction and separation. Better separation compared to silica has been achieved, for example in the separation of sterol esters and waxes, which can both be extracted from the surface of plants such as heather. The separation of the lipids extracted from Calluna vulgaris was quicker and cleaner over expanded starch compared to silica. The purification of these lipids, to remove polar lipids, pigments and sugars could be achieved using 100\% hexane over expanded starch, while the equivalent separations over silica required almost twice the volume of a hexane-ether mixture $(90: 10 \mathrm{v} / \mathrm{v})$. These observations are

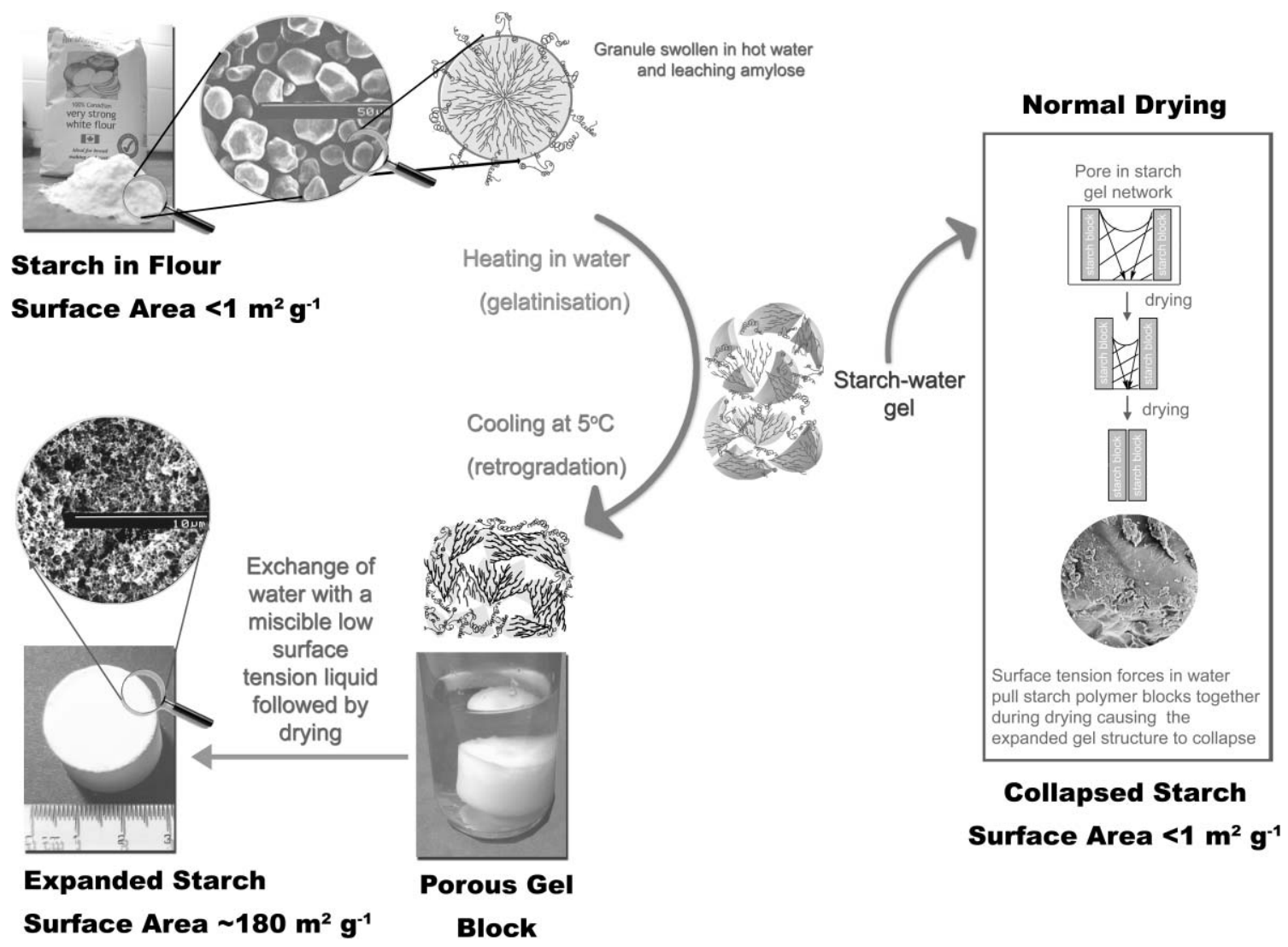

Fig. 6 Diagrammatic representation of the preparation of expanded starch. 
consistent with the measured relative polarities of the two stationary phases ( silica $>$ starch). Other, and less solventdemanding, separations over expanded starch have been consistently observed for a number of complex plant extracts in our laboratory.

Other proven applications for expanded starches include as a catalyst support, ${ }^{21,22}$ and in composites. ${ }^{23}$ We are currently studying other applications.

\section{Increasing the surface area of cellulose}

Cellulose, the most abundant polysaccharide on earth, consists of long linear chains of glucose. Unlike starch, it does not easily gel in water but we have found it possible to increase its surface area by first heating in water and then removing the water with ethanol. Cellulose can, however, be expanded into a higher surface area form by ultrasonic activation. Surface areas increase with time of extraction and with increasing temperature up to $c a .50{ }^{\circ} \mathrm{C}$, although the maximum value we have been able to obtain is $c a .70 \mathrm{~m}^{2} \mathrm{~g}^{-1}$ (Fig. 7). Ultrasonic probe activation can give these values in a matter of minutes, whereas activation in a bath is much slower.

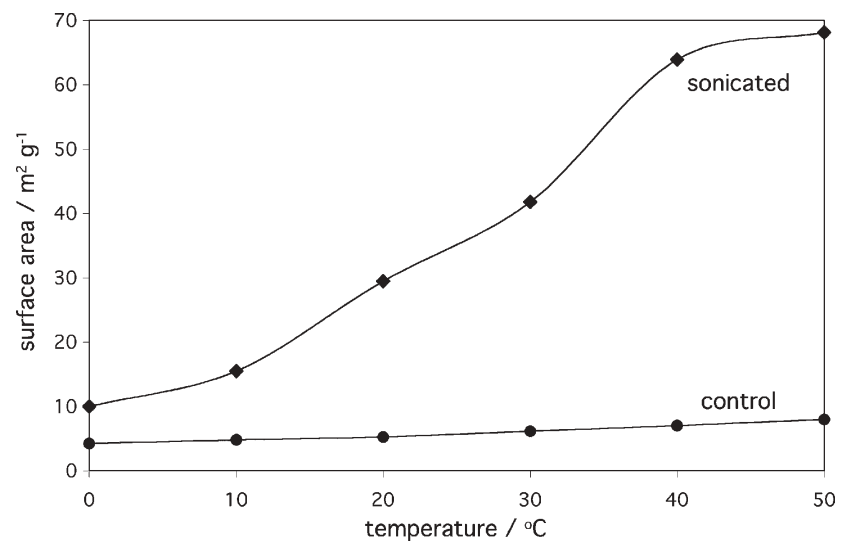

Fig. 7 Effect of temperature upon surface area of cellulose (sonicated in $\mathrm{EtOH}$ for $30 \mathrm{~min}$ ).

These expanded, high surface area forms of cellulose are less stable than expanded starch with respect to water, and require storage in a dry environment. We are currently studying methods of stabilising the materials (e.g. in composites) and investigating applications for these low cost, easy to prepare and biodegradable porous solids. Initial results show separation abilities as a stationary chromatographic phase similar to those achieved using expanded starches, as well as the ability to trap organic molecules from solution. A detailed account of the preparation and applications of expanded cellulose will be published separately.

\section{Chitosan}

Chitosan is deacetylated chitin from the shells of crustaceans, cell walls of fungi and exoskeletons and gut linings of insects, and one of nature's largest volume materials. It is therefore truly sustainable, as well as being significantly different to nature's other large volume, renewable materials cellulose and starch in that it offers a mixture of amino and hydroxyl functions rather than hydroxyl groups alone.

The amino function opens up a number of interesting possibilities including metal binding for the remediation of toxic waste streams, applications as a solid base, and the ability to bind metal complexes for catalytic applications. ${ }^{24-26}$

We have shown that chitosan forms stable (leachingresistant) complexes with palladium and nickel by borrowing surface complexation developed for silica. ${ }^{27}$ The resulting chitosan-metal complexes show comparable activity to the original silica materials in Heck and Suzuki coupling reactions (Pd catalysts) and in Baeyer-Villiger oxidations (Ni catalysts) (Fig. 8).

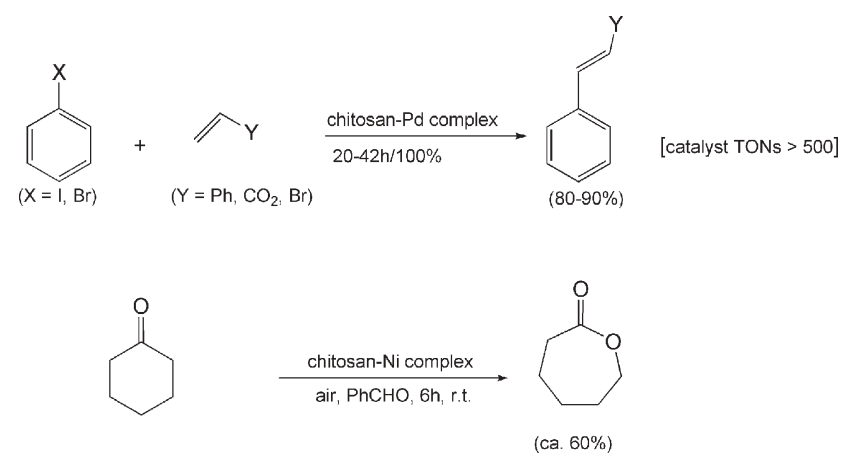

Fig. 8 Reactions catalysed by chitosan-Pd complex catalysts.

The ability to cast thin films of catalytically active materials can be very useful, for example in microreactors and in intensive processing devices, such as spinning disc reactors. We have had some success in casting chitosan films on aluminium substrates, and were then able to modify this to achieve promising catalytic activity, for example in Pd-catalysed oxidations. We have also found it is possible to cast fibres of chitosan mixed with expanded starch, further opening the way for novel applications for these renewable raw materials.

\section{Biomass platform molecules}

We have already described our research with lignin, and specifically with attempts to increase the selectivity of the cracking of this complex natural material to vanillin. This is one of a number of organic compounds that can be made in large quantities from a renewable feedstock. ${ }^{7}$ These should steadily replace the traditional platform molecules derived from petroleum such as ethene, propene and benzene.

In green chemistry we need to apply our clean synthesis methods, including heterogeneous catalysis, to building up these new platform molecules into marketable products. Only by following renewable feedstocks with green chemical processing can we hope to build up a library of truly sustainable and environmentally friendly chemicals.

Two other interesting and very promising biomass platform molecules that we are currently studying are glycerol and succinic acid. Both are readily and sustainably obtainable from large volume raw materials, although the availability of one (glycerol) has been rapidly accelerated by political drivers (demand for biodiesel). ${ }^{6}$ Indeed, the availability and cost of 
these and other biomass platform molecules are likely to be influenced as much by the complex politico-economic issues associated with the inter-related food and bioenergy aspects of the biorefinery as chemical markets.

Glycerol is the co-product in the production of biodiesel (alcohol + triglyceride to ester + glycerol). Given the political pressure and financial incentives to substantially increase the production of biodiesel, the volume of glycerol coming on to markets such as northern Europe will far exceed demand. At the time of writing, in the UK alone, over 300 companies are in the early stages of biodiesel manufacture. Reminiscent of the start of ultra-large volume petroleum production in the 1930s, the energy industry will again result in large volumes of low cost chemicals becoming available, and with reasonable expectancy of continued supply into the foreseeable future. Glycerol has been traditionally manufactured in a multi-step process starting from propene-clearly this will change as the relative price of petroleum and biomass derived molecules changes, although we must not underestimate the costs and relative complexity of working with impure, biologically derived compounds.

As a platform molecule, glycerol has good multiple functionality and a number of immediately valuable or promising products can be envisaged based on the exploitation of green chemistry and green chemical technologies. Some of these are shown in Fig. 9. This could include the use of fast and atomefficient chlorination using $\mathrm{HCl}$ under microwave activation that we have recently described to products including 2,3dichloropropanol that can easily be converted to the valuable industrial chemical, epichlorohydrin, (ironically an intermediate in one traditional route to glycerol starting from propene). ${ }^{28}$ Glycerol reacts with environmentally benign dimethylcarbonate (prepared from the reaction of $\mathrm{CO}_{2}$ with methanol) to form glycerol carbonate, that has been shown to be a valuable intermediate en route to aliphatic polyethers. ${ }^{29}$ Amino acid-based cationic surfactants derived from glycerol have recently been reported. ${ }^{30}$ More established chemistries for glycerol are selective reduction to 1,3-propanediol and selective oxidation to products including glyceric acid. It is vital that we develop the most environmentally benign technologies for doing this, and we are currently studying the use of highly efficient, recoverable heterogeneous catalysts, including supported metals and supported enzymes to achieve this.

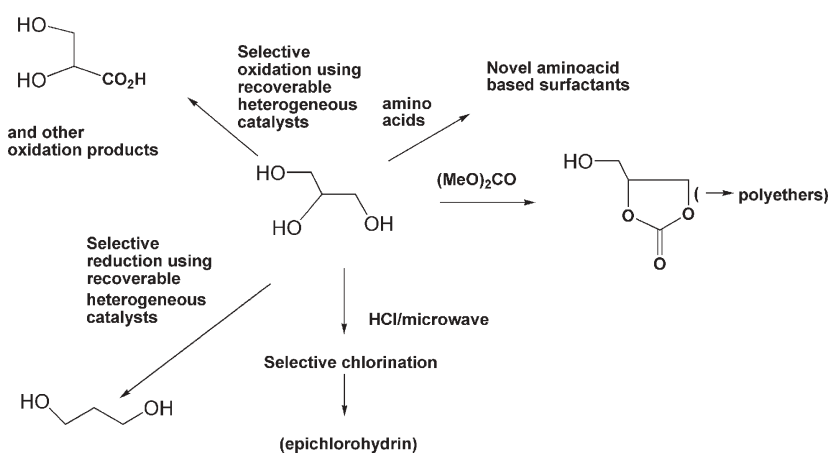

Fig. 9 Green chemical transformations of glycerol to valuable products.
Succinic acid is currently produced largely from petroleum in a multistep process (butane $\rightarrow$ maleic anhydride $\rightarrow$ maleic acid $\rightarrow$ succinic acid), amounting to $c a$. $15 \times 10^{3}$ tpa. It has a number of established markets but these are mostly speciality, as its price excludes its use as a larger volume molecule (up to $€ 8$ per $\mathrm{kg}$ ). ${ }^{31}$ The potential for larger volume use to make new biodegradable plastics, as well as solvents and large volume intermediates is considerable. It has been shown that bio-based succinic acid produced from glucose could be considerably cheaper than the petro-based substance, with an estimated operating cost as low as $€ 0.5$ per $\mathrm{kg},{ }^{31,32}$ easily placing it in the commodity chemical price range as well as having assured sustainability of supply (e.g. from bioprocessing of agro and food by-products). This would open up large new markets, including polymers and solvents.

Examples of the green chemical technologies we are currently studying in relation to succinic acid, in collaboration with biochemical engineers (as well as other bio-platform molecule acids), are shown in Fig. 10. Methodologies that are tolerant of impure and dilute feeds are of particular interest to us given the high energy costs that would be associated with concentrating and purifying fermentation broths.

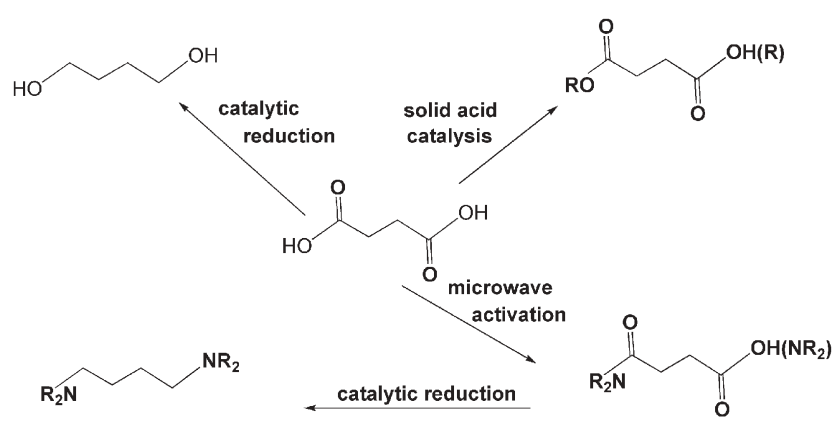

Fig. 10 Green chemical transformations for succinic acid.

\section{Conclusion}

The rapidly escalating costs of petroleum and petrochemicals are likely to accelerate the shift towards chemical products derived from renewable, biological feedstocks. While the majority of proven examples are low volume speciality chemicals, the new Solvay process for manufacturing a commodity chemical (epichlorohydrin) from bio-glycerine shows the way to larger volume chemical production. ${ }^{28} \mathrm{We}$ can expect more and more biorefinery-type facilities where some combination of chemical, energy and food processing are used to add value to biomass feeds. The more use we can make of food and bioenergy by-products to make chemicals, the lower the cost of those chemicals and the quicker we can expect their successful market entry. It is vital to the future of sustainable chemical production that we employ only low environmental impact chemistry to convert these by-products into valuable chemicals and materials. ${ }^{33}$ This is likely to include benign extraction technology (e.g. supercritical $\mathrm{CO}_{2}$ ), physical and green chemical enhancement of cellulose, chitin and starch (e.g. physical expansion), the use of highly efficient heating methods (e.g. microwave activation), and the right 
combination of biochemical and low environmental impact chemical methods to build up biomass platform molecules.

Green Chemistry and the biorefinery is a partnership for a sustainable future.

\section{Acknowledgements}

We are indebted to our many sponsors including EPSRC, DEFRA, the EU, Yorkshire Forward, the University of York and CSL, as well as our many collaborators, notably at the Universities of Newcastle (Chemical Engineering), Manchester (Satake Centre for Grain Processing Engineering) and CSL, and Mr Paul Elliott, Chief Technician at the York Green Chemistry Centre.

\section{References}

1 Feedstocks for the Future, ed. J. Bozell and M. K. Patel, ACS, New York, 2006.

2 Renewable Resources, ed. C. V. Stevens and R. V. Verhe, Wiley, Chichester, 2004.

3 A. J. Ragauskas, et al., Science, 2006, 311, 484.

4 F. E. I. Deswarte, J. H. Clark, J. J. E. Hardy and P. M. Rose, Green Chem., 2006, 8, 39.

5 V. Kalapathy, A. Proctor and J. Schultz, Bioresour. Technol., 2002, $\mathbf{8 5}, 285$.

$6 \mathrm{http}: / /$ www.biodiesel.org/.

7 Top Value Chemicals from biomass, ed. T. Werpy and G. Petoser, http://www1.eere.energy.gov/biomass/pdfs/35523.pdf.

$8 \mathrm{http} / / /$ www.nrel.gov/biomass/biorefinery.html.

9 E. Audsley and J. E. Annetts, Agric. Syst., 2003, 76, 39.

$10 \mathrm{http}: / / \mathrm{www}$.greenchemistry.net.

11 R. Sun, J. M. Lawther and W. B. Banks, Ind. Crops Prod., 1996, $\mathbf{5}, 291$.

12 J. H. Clark, F. E. I. Deswarte and J. J. E. Hardy, PCT Pat. Appl., PCT/GB0502337.9, 2005.

13 State of the Countryside Report, The Countryside Agency, 2001.
$14 \mathrm{http} / / / \mathrm{www} . \mathrm{moorlandassociation.org.}$

15 R. D. Pancost, M. Baas, B. V. Geel and J. S. S. Damste, Org. Geochem., 2002, 33, 675.

16 D. B. Turley, Q. Chaudhry, R. W. Watkins, J. H. Clark and F. E. I. Deswarte, Ind. Crops Prod., 2006, in press.

17 H. L. Hergert, Lignans - natural products of woody plants, ed. J. W. Rowe, Springer Verlag, Berlin, 1989.

18 D. Fengel and G. Wegener, in Wood Chemistry: Ultrastructure, Reactions, ed. W. De Gruyter, Berlin, New York, 1984.

19 V. Budarin, J. H. Clark, F. E. I. Deswarte, J. J. E. Hardy, A. J. Hunt and F. M. Kerton, Chem. Commun., 2005, 2869.

20 V. Budarin, J. H. Clark, J. J. E. Hardy, R. Luque, K. Milkowski, S. J. Tavener and A. J. Wilson, Angew. Chem., Int. Ed., 2006, 45, 3782.

21 J. H. Clark, S. Doi, K. Milkowski and D. J. Macquarrie, Chem. Commun., 2002, 2632.

22 M. J. Gronnow, R. Luque, D. J. Macquarrie and J. H. Clark, Green Chem., 2005, 7, 552.

23 K. Milkowski, J. H. Clark and S. Doi, Green Chem., 2004, 6, 189.

24 D. J. Macquarrie, J. J. E. Hardy, S. Hubert, A. J. Deveaux, M. Bandini, R. Luque and M. Chabriel, in Feedstocks for the Future, ed. J. Bozell ACS, New York, 2006.

25 J. J. E. Hardy, S. Hubert, D. J. Macquarrie and A. J. Wilson, Green Chem., 2004, 6, 53.

26 D. J. Macquarrie and J. J. E. Hardy, Ind. Eng. Chem. Res., 2005, 44, 8499.

27 E. B. Mubofu, J. H. Clark and D. J. Macquarrie, Green Chem., 2000, 2, 53; E. B. Mubofu, J. H. Clark and D. J. Macquarrie, Green Chem., 2001, 3, 23.

28 J. H. Clark, D. J. Macquarrie and M. C. Reid, Green Chem., 2006, 8, 437, http://www.solvaypress.com/pressreleases/O,38695-2$0,00 . h$ tm.

29 G. Rokicki, P. Rakoczy, P. Parzuckowski and M. Sobiecki, Green Chem., 2005, 7, 529.

30 N. Perez, L. Perez, M. R. Infante and M. T. Garcia, Green Chem., 2005, 7, 540 .

31 J. G. Zeikus, M. K. Jain and P. Elankovan, Appl. Microbiol. Biotechnol., 1999, 51, 545.

32 M. Paster, Industrial bioproducts: today and tomorrow, report for the US DoE, 2003.

33 J. H. Clark, Green Chem., 2006, 8, 17. 